\title{
Afinal, o quão coerente é a fala nas comunidades linguísticas?
}

\author{
Ismael Cunha FREITAS (1) \\ Universidade Federal do Rio Grande do Sul (UFRGS) \\ Bruna Silva dos SANTOS (1) \\ Universidade Federal do Rio Grande do Sul (UFRGS)
}

OPEN ACCESS

EDITADO POR

Raquel Freitag

AVALIADO POR

Ronald Mendes

SOBRE OS AUTORES

Ismael Cunha Freitas

Contribuiu com Bruna Silva dos

Santos. Papéis: escrita -

rascunho original, análise e

edição.

Bruna Silva dos Santos Contribuiu com Ismael Cunha

Freitas. Papéis:

conceptualização, escrita -

rascunho original.

DATAS

Recebido: 18/06/2020

Aceito: $25 / 07 / 2020$

Publicado: 06/08/2020

COMO CITAR

Freitas, I. C.; Santos, B. S.

(2020).

Afinal, o quão coerente é a fala nas comunidades linguísticas? - Revista da Abralin, v. 19, n. 2, p.

\section{RESUMO}

Fundamentado nos trabalhos de Labov (2006), Becker (2016), Oushiro (2015, 2019), Mendes (2016; 2019) e Eckert (2008), Gregory Guy promove em sua fala uma discussão acerca da coerência dialetal nas comunidades de fala. Em primeiro lugar, Guy procura evidenciar como a experiência linguística individual é usada para construir e performar identidades sociais. Em segundo, partindo dos trabalhos de Labov e de Becker, o conferencista toma como premissa a heterogeneidade social e individual da língua, para, por meio das pesquisas de Guy, de Mendes e de Oushiro, discutir a noção de coerência dialetal. Dessa forma, calcado em análises de dados empíricos, o palestrante prevê uma diminuição da coerência impulsionada pelo contato entre línguas e pela simplificação das complexidades linguísticas promovidos pela globalização.

\section{ABSTRACT}

Based on the works of Labov (2006), Becker (2016), Oushiro (2015, 2019), Mendes (2016; 2019), and Eckert (2008), Gregory Guy promotes in his speech a discussion about dialectal coherence in speech communities. First, Guy seeks to highlight how individual linguistic experience is used to build and perform social identities. Second, he takes as a premise the social and individual heterogeneity from the works of Labov and Becker in order to discuss the notion of dialectal cohesion through the investigations of Guy, Mendes, and Oushiro. Thus, founded on empirical data analysis, the lecturer predicts that globalization increases the contact between languages and the 


\section{REVISTA DA ABRALIN}

simplification of linguistic complexities provoking a decrease in linguistic coherence.

\section{PALAVRAS-CHAVE}

Coerência. Comunidade de fala. Significado social.

\section{KEYWORDS}

Coherence. Speech community. Social meaning.

Até que ponto os falantes em uma comunidade usam, de forma paralela, as múltiplas variáveis disponíveis a eles? É através desse questionamento que podemos compreender a construção da hipótese do professor Gregory R. Guy acerca da coerência dialetal - conceito que busca investigar se as múltiplas variáveis coexistentes se distribuem similarmente extra e intralinguísticas na comunidade de fala. Procurando responder se há ou não sistematicidade na correlação entre variáveis, isto é, se elas possuem simultaneamente uma estratificação social, linguística e estilística, o conferencista apresenta alguns estudos quantitativos e conclui que a coerência depende da estrutura social. E, com isso, a partir dos resultados analisados, Guy infere que quanto maior for a diferenciação social mais incoerentes são os padrões de uso das variáveis linguísticas. Partindo dessa premissa, o horizonte final da fala parece ser a coerência face à globalização moderna. Segundo a argumentação, há uma tendência das línguas a se tornarem mais incoerentes, pois, a globalização amplia os horizontes linguísticos e aumenta o contato entre as línguas, promovendo uma grande estratificação social. Com a finalidade de apresentar a comunicação ao leitor, tentaremos reconstruir os passos que o professor toma em sua arguição.

Assim, em primeiro lugar, devemos nos perguntar: o que é língua, como defini-la e onde encontrá-la?

O conceito de língua que fundamenta o trabalho é o de um conjunto de elementos linguísticos presentes na mente e verificados no uso dos falantes. Encerrando nessa definição um viés descritivo, o conferencista aponta que o objeto de análise linguística deve ser as comunidades de falas complexas, formadas por falantes diversos. Nesse sentido, constituída por uma heterogeneidade ordenada, a língua é inerentemente variável e inerentemente estruturada (cf. WEINREICH et al., 2006 [1968]). Diante dessa diversidade e variabilidade, Guy questiona-se: há coerência no uso da língua?

Antes, porém, faz-se necessário compreender o que é uma comunidade de fala. Conforme enunciado pelo professor, para constituir uma comunidade de fala os falantes precisam: compartilhar elementos linguísticos; compartilhar normas e avaliações acerca da língua; estabelecer uma densidade de comunicação interna relativamente alta. Na sequência, Guy apresenta dois tipos de comunidades de fala. O primeiro refere-se às comunidades "aninhadas", isto é, que se aglutinam e se restringem a grupos maiores ou menores, como uma boneca russa linguística. O segundo tipo diz respeito às comunidades interseccionais, compostas por membros que fazem parte simultaneamente 


\section{REVISTA DA ABRALIN}

de duas comunidades de fala. Configurando, então, a primeira dimensão com a qual Guy aborda o tema da conferência, a comunidade de fala remete a uma estrutura social em que as variáveis linguísticas assumem uma função constituidora e delimitadora.

A segunda dimensão diz respeito à variação interna ao falante. Mais especificamente, relacionase à heterogeneidade na fala de cada indivíduo, que usa diferentes variáveis de acordo com o estilo, o contexto, o interlocutor etc. Weinreich, Labov e Herzog entendem que o "domínio de um falante nativo de estruturas heterogêneas [...] é parte da competência linguística monolíngue" (WEINREICH et al., 2006, p. 36). Isto posto, Guy afirma que a língua é a forma mais expressiva de comportamento social disponível a nós. Ela é a ferramenta central para construir e performar nossas identidades.

Na continuidade, Guy nos presenteia com um exemplo simpático da experiência linguística de seu próprio filho. Na infância, Jesse teve contato com o inglês de três países diferentes: Estados Unidos, Austrália e Canadá. Nos dois primeiros, há diferenciação fonêmica entre / / e /a/, enquanto no Canadá as duas vogais não têm valor distintivo. Na sua trajetória, Jesse adquiriu essa diferenciação antes de mudar-se para Toronto e a manteve nos anos iniciais em que morou lá. No entanto, em algum momento parou de produzir a distinção. Quando o pai o interroga sobre o fenômeno, este devolve que, sim, consegue fazer a diferenciação, mas questiona o porquê de querer produzi-la. Guy compreende esse momento como crucial e, refinando a pergunta do próprio filho, o conferencista indaga: por que você diria algo de uma forma e não de outra? No caso específico do menino, tratava-se do desejo de aceitação e pertença ao novo grupo em que estava se inserindo. Jesse aprendeu a pronúncia canadense e a adotou a partir de uma escolha pessoal para construir e expressar uma identidade social. E, como resultado dessa adoção, ele aumentou a coerência do grupo.

No entanto, quando olhamos para o comportamento individual de Jesse, podemos enxergar esse episódio como assistemático. Nesse sentido, para explicar as variações linguísticas dos indivíduos é necessário entender a comunidade em que ele está inserido. As comunidades são fontes de associações indiciais, das quais os falantes evocam para fazer escolhas de uso e, por decorrência, performar identidades. Pode-se notar que essas associações são multidimensionais, pois compreendem uma série de estratificações sociais. Considerando isso, Guy se pergunta qual seria o nível de agentividade dos falantes acerca de seu uso, o quão fluido são as escolhas individuais a respeito das variáveis e o quão coerente é o comportamento da comunidade em relação a suas avaliações linguísticas e os significados sociais.

A fim de ilustração, Guy discute o trabalho de Mendes (2016) sobre a concordância nominal em São Paulo, variável saliente que possui uma norma cristalizada na comunidade. Nesta pesquisa, o autor fez uso de quatro vozes masculinas e aplicou a técnica matched-guised (LAMBERT, 1967 apud LABOV, 1972) - usada para observar a avaliação subjetiva de ouvintes em relação a uma variável. Foram observados três componentes principais nas respostas (competência linguística, amigabilidade e efeminidade) com o objetivo de investigar a percepção de masculinidade. Os resultados de Mendes mostraram que a produção da marca zero é entendida como proveniente de pessoas menos escolarizadas e menos efeminadas. Para todos os ouvintes, a escolaridade foi a variável mais relevante. Assim, como fator mais significativo, a escolaridade tem efeito sobre a avaliação da fala 


\section{REVISTA DA ABRALIN}

individual. Logo, quanto mais saliente ${ }^{1}$ for uma variável na comunidade de fala, mais relacionada à concepção de certo e errado ela é.

Desse ponto, Guy volta-se para Labov para mostrar um exemplo clássico de uma variável saliente: a estratificação do (r) em Lower East Side. Nesse estudo, Labov verificou que a incidência de $/ \mathrm{r} /$ aumentava em relação à formalidade do contexto, definindo-a, assim, como uma marca prestigiada. Na continuidade, Guy faz uso de um segundo estudo na cidade de Nova York, cinquenta anos após o primeiro (BECKER, 2016). Este último evidenciou a correlação entre o alçamento das vogais em BOUGHT e BAD e a presença/ausência de (r). Os resultados revelaram uma mudança das variáveis antes predominantes para Labov, demonstrando aí uma forte correlação entre as três variáveis, especialmente entre a vogal de BOUGHT e o /r/.

Em uma pesquisa do próprio conferencista no Rio de Janeiro, Guy (2013) também procurou correlacionar quatro variáveis: duas fonológicas (apagamento do / s / e desnasalização em sílabas átonas finais) e duas sintáticas (concordância nominal e verbal). No entanto, interessa questionar o resultado da correlação da dupla de variáveis fonológicas entre si, pois, com pouca correlação, pode-se entender que ambas variáveis são mais abstratas e, portanto, seus significados sociais são menos evidentes. De qualquer maneira, a conclusão de Guy demonstra que os falantes tendem a correlacionar variáveis que se assemelham.

Em outro estudo, agora na cidade de São Paulo (GUY et al., 2019), a investigação concentrou-se em seis variáveis, três fonológicas e três sintáticas. Os resultados desta pesquisa demonstram os efeitos da consciência do falante em relação às correlações operadas: por exemplo, as três variáveis sintáticas e o /r/ retroflexo são variáveis salientes e, portanto, correlacionam-se acima do nível da consciência, enquanto que, por outro lado, o apagamento do (r) em coda, por ser uma variável fonológica não saliente, correlaciona-se com as variáveis sintáticas de forma inconsciente. Do mesmo modo, as duas variáveis fonológicas - apagamento do (r) e alternância do /r/ - também se correlacionam abaixo do nível da consciência social.

Por fim, Guy propõe algumas conclusões acerca da coerência dialetal. O enquadramento geral da problemática parece se dar por conta das mudanças na estrutura social propiciadas pela globalização. Através do crescimento de falantes L2 e D2 e o contato entre línguas, as complexidades linguísticas tendem a inibir-se nas línguas ocidentais. De fato, as diversidades sociais e o contato entre línguas promovem o crescimento da incoerência refreando a preservação e a transmissão de complexidades linguísticas. Todavia, por meio da transmissão intergeracional, o conferencista prevê que as línguas manterão sua coerência, mesmo que não sejam tão coerentes como seus estágios anteriores.

1 Compreende-se como uma variável acima do nível de consciência dos falantes e cristalizada como norma na comunidade de fala. 


\section{REVISTA DA ABRALIN}

\section{REFERÊNCIAS}

THE (in)coherence of linguistic communities. Conferência apresentada por Gregory R. Guy [s.l., s.n], 2020.1 vídeo (1h 26min 09s). Publicado pelo canal da Associação Brasileira de Linguística. Disponível em: https://www.youtube.com/watch?v=JKBE9vW1pL0. Acesso em: 11 junho de 2020.

BECKER, K. Linking community coherence, individual coherence, and bricolage: The co-occurrence of ( $\mathrm{r}$ ), raised bought and raised bad in New York City English. Lingua, v. 172-173, p. 87-99, march-april, 2016.

ECKERT, P. Variation and the indexical field. Journal of Sociolinguistics, v. 12(4), p. 453-476, 2008.

GUY, G. R.; MENDES, R. B.; OUSHIRO, L. Indexicality and cohesion. In: International Conference on Language Variation in Europe 10, 2019, Leeuwarden/Ljouwert. ICLaVE10 Program, 2019. v. 1.

GUY, G. The cognitive coherence of sociolects: How do speakers handle multiple sociolinguistic variables? Journal of Pragmatics, v. 52, p. 63-71, 2013.

LABOV, W. Sociolinguistic Patterns. Philadelphia: University of Pennsylvania Press, 1972.

LABOV, W. The social stratification of English in New York City. - 2.ed. - New York: Cambridge University Press, 2006.

MENDES, R. B. Diphthongized (en) and the indexation of femininity and paulistanity. Cadernos de Estudos Linguisticos, v. 58, p. 1$23,2016$.

WEINREICH, U.; LABOV, W.; HERZOG M. Fundamentos empíricos para uma teoria da mudança linguística. Trad. Marcos Bagno. São Paulo: Parábola Editorial, 2006 [1968]. 